\title{
CHARACTERISTICS OF WATER SURFACE PROFILES OF OPEN CHANNEL FLOW WITH LEVEE OVERTOPPING
}

\author{
SHINSUKE NAMOTO ${ }^{1}$, TADAHARU ISHIKAWA ${ }^{2} \&$ TAKASHI KOJIMA ${ }^{1}$ \\ ${ }^{1}$ TOKEN C.E.E. Consultants Co., Ltd., Tokyo, Japan. \\ ${ }^{2}$ Tokyo Institute of Technology, Tokyo, Japan.
}

\begin{abstract}
The risk of levee overtopping has increased because of the frequency of severe rain storm due to climate change. Flow depth over levees is a design parameter that must be considered, but standards have not been agreed on. In this study, the mechanisms of levee overtopping are investigated by analyzing the water surface profile in an open channel with side-overflow using a 2-D shallow water model on an unstructured triangular mesh system. Scenarios in which the channel capacity decreases downstream were considered; the first when the channel slope decreases and the second a "Y-shape" confluence of two river channels. The computation for the slope changing channel exhibited the following results: (1) levee overtopping occurred not only in the downstream channel but also in the upstream channel due to the backwater effect, (2) the overflow depth was much smaller than the value predicted for normal flow without side-overflow, and (3) the water stage at the levee crown was lower than the transversely averaged one around the slope change section due to the 2-D flow effect. The computational results for the confluent channel had the tendencies common to those for the slope changing channel, but further showed: (4) the overflow depth anomaly appeared at the inner corner of the confluence with an increase in the confluent angle, which suggested that the delta area between the confluent channels could be used as a detention basin by armoring the short reach at the corner.

Keywords: 2-D flow simulation, channel slope change, confluence, levee overflow depth, levee reinforcement, numerical experiment
\end{abstract}

\section{INTRODUCTION}

Global climate change has increased the frequency of rain runoff exceeding the capacity of conventional flood control measures, and several recent flood disasters have been caused by levee overtopping. Increasing river channel capacity is often difficult because of intensive land use, so reinforcement of earth levees by surface armoring is considered for mitigation (JSCE report, 2008). However, standards of overflow depth for levee armoring design have not been defined.

Suga et al. showed that a simple pavement on the levee crown would prolong the life of earth levees significantly when the overflow depth is less than $20 \mathrm{~cm}$ based on the results of hydraulic model tests [1]. Ishikawa presented a 1-D perturbation analysis of the water surface profile for prismatic channel flow with side-overflow and suggested that the levee overflow depth is significantly lower than the value predicted for normal flow without side-overflow [2]. According to a recent flood report [3], a newly constructed earth levee with a uniformly paved levee crown endured against failure for a long duration during overtopping because the overflow was evenly distributed over a long distance. This suggests that a relatively light levee crown pavement can mitigate against overtopping if the overflow depth is not large.

In this study, the basic characteristics of levee overtopping were numerically investigated on open channel flow with side-overflow using a 2-D shallow water model. Two conditions in which the channel capacity decreases downstream due to an abrupt decrease in channel slope (A-series) and a "Y-shape" confluence of two river channels (B-series) were considered. 


\section{METHODOLOGY}

\subsection{Numerical model}

A shallow water flow model developed for tsunami run-up simulation [4] was used. In the model formulation, the hyperbolic differential equations were converted to finite difference equations by the finite volume method on an unstructured triangular mesh system [5], and the Eulerian method was adopted for calculating the flood front to avoid so-called "C-property collapse" [6].

The flow rate over the levees was calculated using the following formula proposed by [7]:

$$
q=\left\{\begin{array}{lc}
0.35 h_{1} \sqrt{2 g h_{1}} & \text { if } h_{2} / h_{1} \leq 2 / 3 \\
0.91 h_{2} \sqrt{2 g\left(h_{1}-h_{2}\right)} & \text { otherwise }
\end{array}\right.
$$

where $q$ is the unit width flow rate over the levee, and $h_{1}$ and $h_{2}$ are the water surface heights on the upstream and downstream sides of overflow from the levee crown, respectively.

\subsection{Experimental condition}

Figure 1 shows the experimental conditions for the A-series experiments. The channel is a straight rectangular sectional channel having a constant width of $100 \mathrm{~m}$ and a constant levee height of $3 \mathrm{~m}$, and the channel slope changes from $\theta_{1}$ to $\theta_{2}$ (the values of which are listed in Table 1). Manning's roughness was assumed as 0.03 . The upstream discharge was assumed as bankful discharge, and the downstream water surface level was assumed to be equal to the levee crown level. Levee overtopping was expected to occur around the slope changing section, as illustrated in the figure.

Figure 2 shows the experimental conditions for the B-series experiments. The channel slope $\theta_{3}$ and the levee height $H_{0}$ were assumed to be constant throughout the entire channel reach. Three conditions were considered by changing the confluent angle $\theta_{4}$, as listed in Table 2. The upstream discharge and the downstream water surface level were the same as those for the A-series experiment. Levee overtopping was expected to occur around the confluence section.

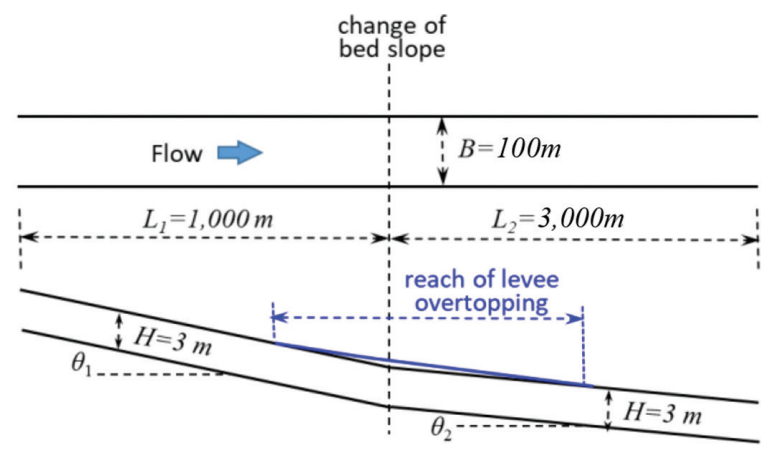

Figure 1: Experimental conditions (A-series: slope change) 
Table 1: A-series calculation conditions

\begin{tabular}{lll}
\hline Case \# & Upstream slope $\theta_{1}$ & Downstream slope $\theta_{2}$ \\
\hline A-1 & $1 / 200$ & $1 / 300$ \\
A-2 & Do. & $1 / 400$ \\
A-3 & Do. & $1 / 500$ \\
\hline
\end{tabular}

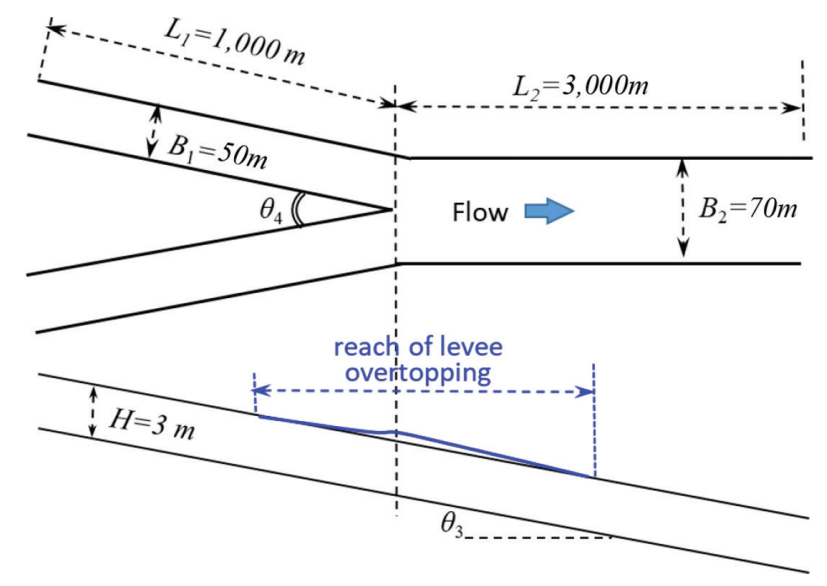

Figure 2: Experimental conditions (B-series: confluence)

Table 2: B-series calculation conditions

\begin{tabular}{lll}
\hline Case \# & Channel slope $\theta_{3}$ & Confluent angle $\theta_{4}$ \\
\hline B-1 & $1 / 300$ & $30^{\circ}$ \\
B-2 & Do & $60^{\circ}$ \\
B-3 & Do & $90^{\circ}$ \\
\hline
\end{tabular}

\section{RESULTS AND DISCUSSIONS}

\subsection{A-series experiments}

Figure 3 shows the water surface profiles at the channel center line $H(x)$, and Fig. 4 shows the longitudinal variation of volume flux $Q(x) . H(x)$ and $Q(x)$ decreased downstream from the section in which slope decreases because of side-overflow and approached to the bankful flow condition. In the upstream reach, side-overflow occurred due to the backwater from the section of channel slope change although the discharge was less than the bankful discharge.

Figure 5 shows the normal flow depths corresponding to the local flow rate $Q(x)$ which were calculated by the Manning's formula without considering the side-overflow effect:

$$
H_{N}(x)=\left\{(n Q(x)) /\left(B \theta_{2}^{1 / 2}\right)\right\}^{3 / 5}
$$




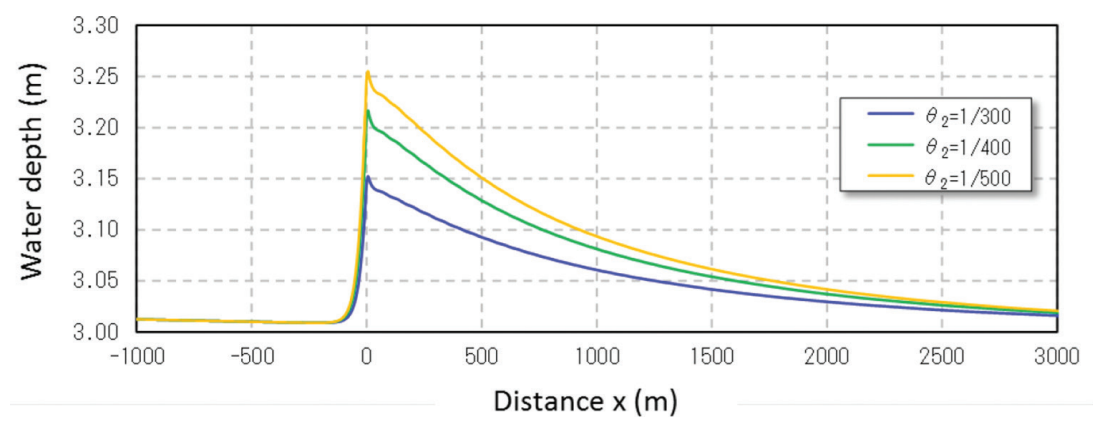

Figure 3: Water surface profile along channel center line

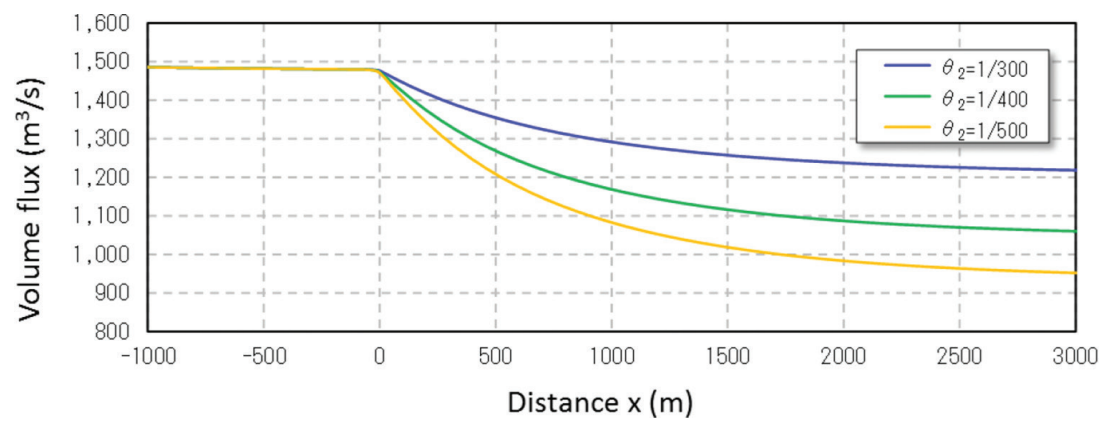

Figure 4: Longitudinal variation of volume flux

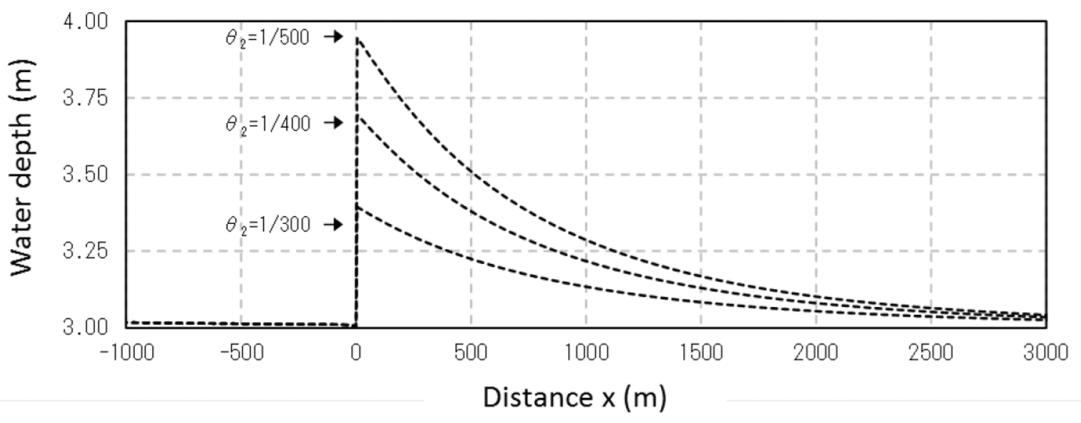

Figure 5: Water surface profile estimated from normal flow conditions

where $H_{N}(x)$ is the normal flow depth, $\mathrm{n}$ is Manning's roughness, $Q(x)$ is local flow rate, $B$ is the channel width, and $\theta_{2}$ is the channel slope. Because Eq. (2) gave values much larger than those for the flow with side-overflow, it can be concluded that a simple prediction of overtopping depth based on the normal flow depth would result in an excessive armor design.

Figure 6a shows the dimensionless overflow depth normalized with the channel depth, $h(x)=H(x) / H_{0}$, near the section of channel slope change, while Fig. 6b shows the excess discharge normalized with bankful discharge, $q(x)=\left\{Q(x)-Q_{0}\right\} / Q_{0}$. The $h(x)$ and $q(x)$ decreased with $\theta_{2}$, but after scaling them by $1 / \theta_{2}$ and $\left(1 / \theta_{2}\right)^{1 / 2}$, respectively, each can be expressed by single curves as shown in Fig. $7 \mathrm{a}$ and $\mathrm{b}$. 


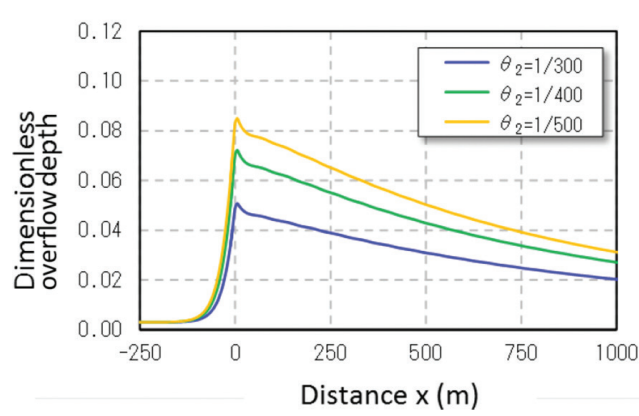

Figure 6(a): Dimensionless overflow depth

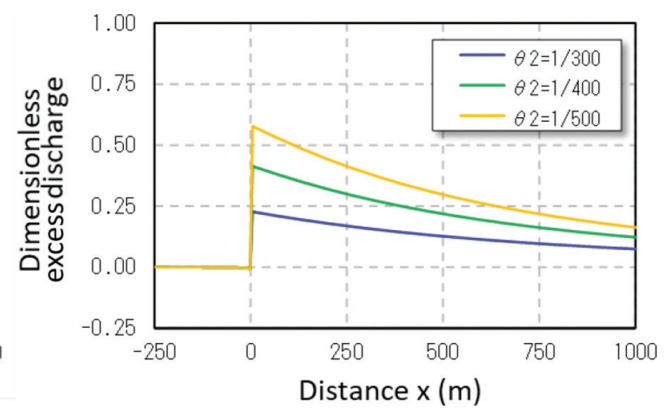

Figure 6(b): Dimensionless excess discharge

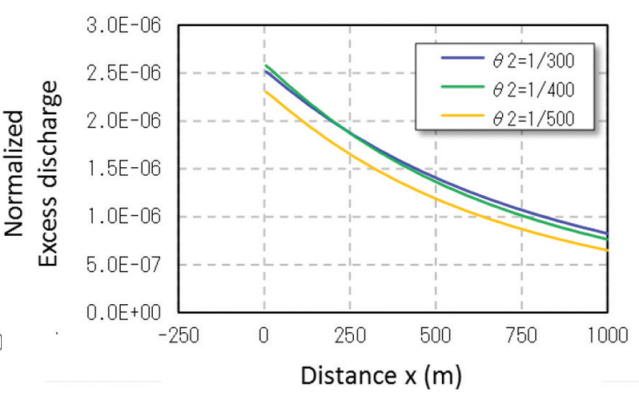

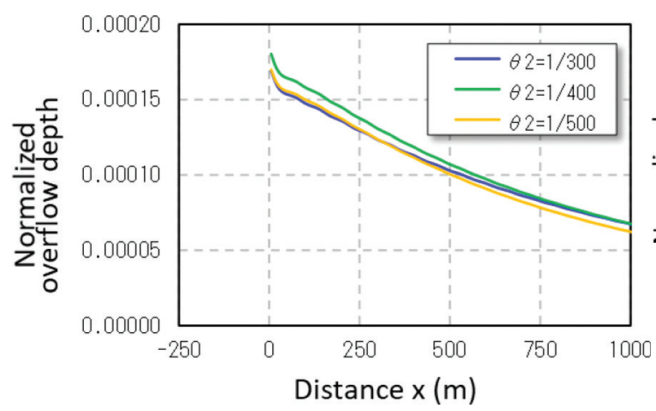

Figure 7(b): Excess discharge scaled by $\left(1 / \theta_{2}\right)^{1 / 2}$

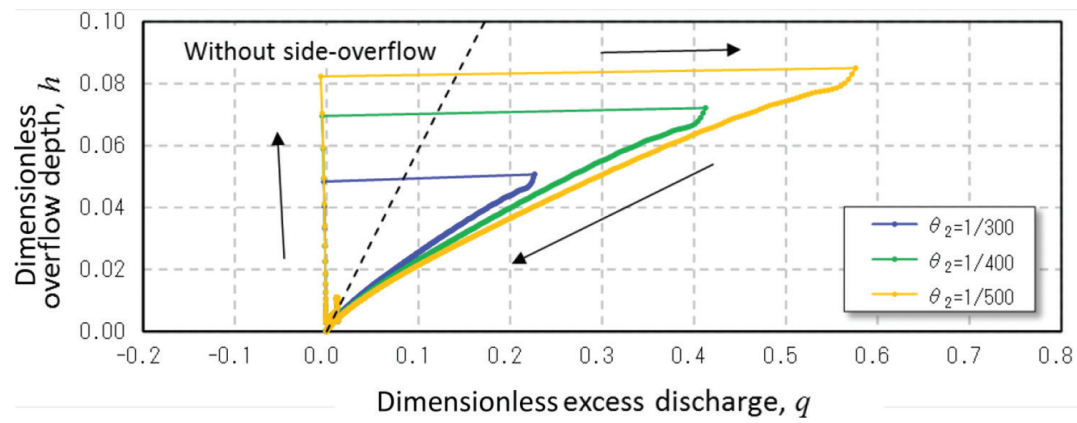

Figure 8: Correlation between $\mathrm{q}$ and $\mathrm{h}$

Figure 8 illustrates the relationship between $q(x)$ and $h(x)$, in which the arrows indicate the direction from the upstream to the downstream. Note that the bankful discharge changes across the section of channel slope change. The bankful flow condition at the upstream end section is placed at the origin of the diagram. The flow condition moves upper left because the dimensionless depth $h$ increases due to the backwater from the slope-change section while $q$ decreases due to side-overflow. Because of the abrupt change of $Q_{0}$ at the slopechange section, the dimensionless excess discharge, $q$, jumps to the positive side with the same $h$. After then the flow condition approaches the bankful condition at the origin. The black broken line in the figure indicates the relationship between $q$ and $h$ obtained from 
Eq. (2) which is located higher than the simulation results (colored lines). This fact means that the actual overflow depth is much smaller than the value predicted from a relationship for normal flow without side-overflow.

Figure 9 shows the velocity vectors on a color counter map of water surface level measured from the levee crown. Note that the calculation result is shown for a half of channel from the center line $(y>0)$ because of the flow symmetry. There is a water surface rise at the channel center just below the slope-change section $(x>0)$, which means that the water stage at the levee crown is lower than the transversely averaged one.

\subsection{B-series experiments}

Figure 10 shows the longitudinal water surface profiles at the channel center lines. The water surface rises sharply around the confluent section over the levee crown $(3 \mathrm{~m})$, and decreases gradually to the bankful condition, as was observed in the A-series experiments (see Fig. 3).

Figure 11 shows the velocity vectors on a color counter map of water surface level measured from the levee crown. There was a significant rise in water surface at the inside corner just upstream from the confluent section, which caused overflow to the delta area between the two confluent channels.

Figure 12 summarizes the results of the three calculations (B-1, B-2 and B-3) for maximum overflow depth at the inner corner of the confluence. The water surface anomaly over the levee crown increases with $\sin \left(\theta_{4} / 2\right)$. The value at $\theta_{4}=0$ (red dot) was estimated from the result of the A-series experiments for the same channel capacity reduction.

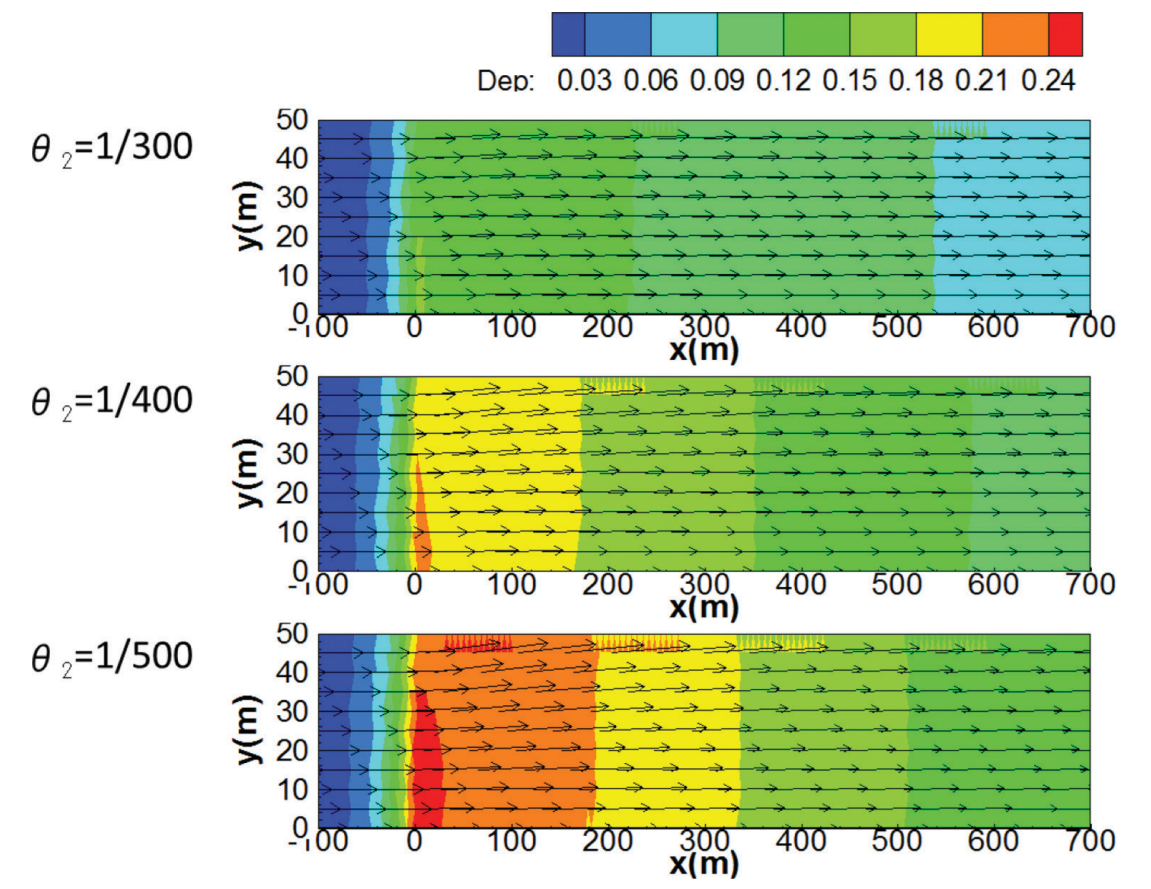

Figure 9: Flow field near slope-change section 


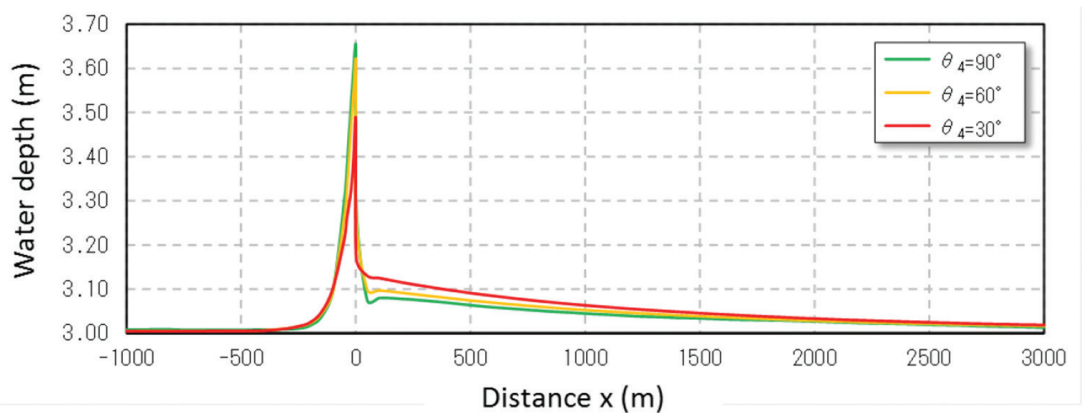

Figure 10: Water surface profiles at the channel center line of confluent channels
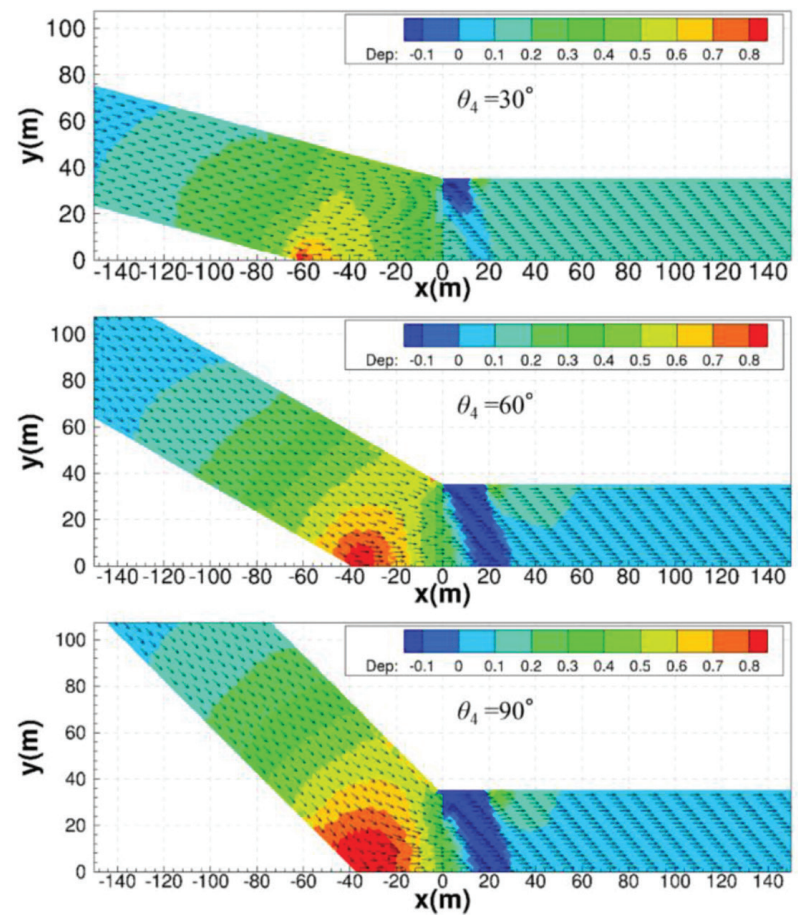

Figure 11: Flow field near the confluence section

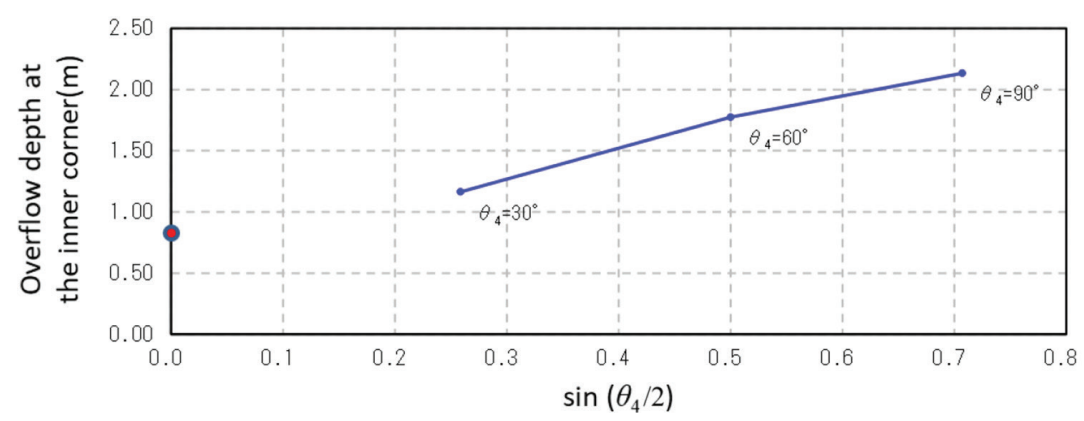

Figure 12: Overflow depth at inner corner 


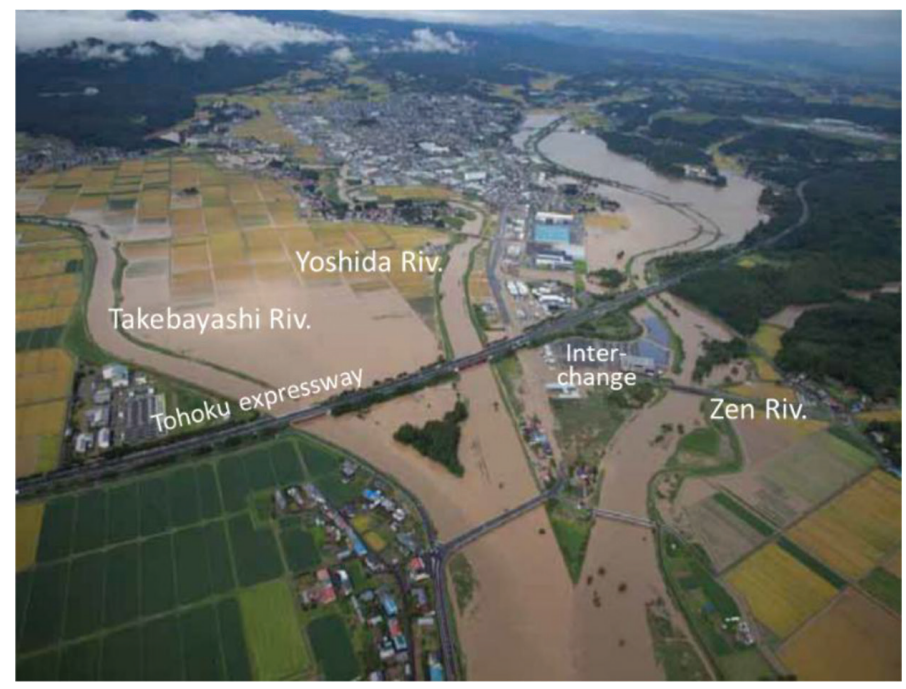

Figure 13: Aerial photograph of flooding in Yoshida River watershed

Figure 13 shows an aerial photograph of flooding that occurred in the watershed of the Yoshida River in 2015 when the levees were not broken except at the upstream reach of the Zen River. The majority of the flooding was caused by levee overflow at the inner corners of the river confluences. The delta area between Takebayashi and Yoshida Rivers is used for paddy fields because it is prone to flooding, while the delta area between the Yoshida and Zen Rivers was recently developed for industrial use after an expressway interchange was located there.

Considering the flow characteristics obtained from the numerical analysis, the levee near the inner corner of the latter confluence should be higher than the outside bank. The delta area of the former, on the other hand, can be used as a detention basin to reduce the discharge downstream by reinforcing the levees against overtopping. The levee height and design against overtopping for both cases will need to be determined using numerical simulation of the flow with side-overflow for the actual river topography.

\section{CONCLUSION}

A series of 2-D numerical experiments on open channel flow with side-overflow were performed for conditions in which the channel capacity was decreased downstream due to an abrupt channel slope decrease and a "Y-shape" confluence. The conclusions are as follows:

1. Levee overtopping occurs not only in the downstream reach from the section with the channel capacity reduction but also in the upstream reach where the discharge is less than the bankful discharge due to the backwater effect.

2. The levee overflow depth is much smaller than the value predicted by the relationship for normal flow without side-overflow. Therefore, it can be concluded that a simple prediction of overtopping depth based on the normal flow depth would result in an excessive armor design.

3. A significant rise in water surface occurs at the inner corner just upstream from the confluent section, which induces a large overflow to the delta area between the confluent channels. The water surface anomaly over the levee crown increases with $\sin \left(\theta_{4} / 2\right)$ where $\theta_{4}$ is the angle of confluence. 


\section{REFERENCES}

[1] Suga, K., Ishikawa, T. \& Kasai, T., The characteristics of failure of embankments by overtopping. Annual Journal of Hydraulic Engineering, 25, pp. 355-360, 1981. https://doi.org/10.2208/prohe1975.25.355

[2] Ishikawa, T., Water surface profile of a flow decreaseng discharge by side wall overtopping. Annual Journal of Hydraulic Engineering, 26, pp. 417-422, 1982. https://doi.org/10.2208/prohe1975.26.417

[3] Ministry of Land, Infrastructure and Transport, available at http://www.thr.mlit.go.jp/ kasen/syussuisokuhou/newpage1.files/20150917_17h.jiten_sokuhou2.pdf, 2017.

[4] Akoh, R., Ishikawa, T., Hatakeyama, S., Kojima, T., Tomaru, M. \& Nakamura, T., The flood simulation of the 2011 off the Pacific Coast OF Tohoku Earthquake Tsunami in urban area of Kamaishi Bay. Journal of Japan Society of Civil Engineers, Ser. B1 (Hydraulic Engineering), 71(1), pp. 16-27, 2015. https://doi.org/10.2208/jscejhe.71.16

[5] Roe, P.J., Approximate riemann solvers, parameter vectors, and difference schemes. Journal of Computational Physics, 43, pp. 357-372, 1981. https://doi.org/10.1016/0021-9991(81)90128-5

[6] Brufau, P., Vázquez-Cendón, M.E. \& García-Navarro, P.A., Numerical model for the flooding and drying of irregular domains. International Journal for Numerical Methods in Fluids, 39, pp. 247-275, 2002. https://doi.org/10.1002/fld.285

[7] Honma, H., Coefficient of flow volume on low overflow weir. Civil Engineering, JSCE, 26(2), pp. 635-645, 1940. (in Japanese) 